\title{
Fitotoxicidade de clomazone associado com dietholate à cultura do trigo ${ }^{1}$
}

\section{Phytotoxicity clomazone associated with dietholate the crop wheat}

\author{
Maicon Fernando Schmitz² Leandro Galon²; Bruna Piovesan²; Matheus Freitas de Souza ${ }^{3}$; César \\ Tiago Forte ${ }^{2}$; Gismael Francisco Perin ${ }^{2}$
}

Resumo - Na atualidade torna-se importante testar novas alternativas de moléculas herbicidas, mesmo que não sejam registradas para o controle de plantas daninhas infestantes do trigo, para avaliar a fitotoxicidade à cultura e a possibilidade de manejar plantas daninhas resistentes aos produtos utilizados para esse fim. Diante disso, um experimento foi realizado para avaliar a fitotoxicidade do herbicida clomazone associado ou não ao safener dietholate aplicados à cultura do trigo. $\mathrm{O}$ experimento foi realizado em delineamento inteiramente casualizado, arranjado em esquema fatorial $(5 \times 4)+2+2$, com quatro repetições. No fator A alocou-se as doses de dietholate $(0,120,240,360$ e $480 \mathrm{~g}$ para $100 \mathrm{~kg}$ de semente) e o no B as doses de clomazone $(0,198,396 \mathrm{e}$ $\left.594 \mathrm{~g} \mathrm{ha}^{-1}\right)$. Os tratamentos adicionais foram constituídos pelas testemunhas infestadas e sem herbicida, e a aplicação em pós-emergência de iodosulfuron-methyl $\left(5 \mathrm{~g} \mathrm{ha}^{-1}\right)$ e pyroxsulam (18 $\mathrm{g}$ $\left.\mathrm{ha}^{-1}\right)$. O incremento das doses de clomazone ocasionou o aumento da fitotoxicidade ao trigo, associado ou não ao protetor. O dietholate não apresentou capacidade de proteger o trigo dos efeitos fitotóxicos do herbicida clomazone. Não é recomendado o uso do clomazone associado ao diethole para o controle de plantas daninhas infestantes do trigo. O pyroxsulam foi o herbicida que causou menores injúrias ao trigo.

Palavras-chaves: Lolium multiflorum; Raphanus sp.; safener; Triticum aestivum

Abstract - Nowadays it has become important to test new alternatives herbicide molecules, even if they are not registered for the control of weeds that infest wheat, to evaluate the phytotoxicity to culture and the ability to manage resistant weeds to the products used for this purpose. Thus, an experiment was conducted to evaluate the Phytotoxicity of clomazone associated or not to the dietholate safener applied on wheat. The experiment was conducted in a completely randomized design, arranged in a factorial scheme $(5 \times 4)+2+2$, with four replications. In the factor allocated to dietholate doses $(0,120,240,360$ and $480 \mathrm{~g}$ per $100 \mathrm{~kg}$ of seed $)$ and the B clomazone doses $(0$, 198, 396 and $\left.594 \mathrm{~g} \mathrm{ha}^{-1}\right)$. Additional Treatments were the control treatments infested and without the application of herbicide, and the application in post-emergence of iodosulfuron-methyl ( $5 \mathrm{~g} \mathrm{ha}^{-}$ ${ }^{1}$ ) and pyroxsulam $\left(18 \mathrm{~g} \mathrm{ha}^{-1}\right)$. The increase in clomazone doses caused increased phytotoxicity to wheat, with or without the safener. The dietholate showed no ability to protect the wheat from the phytotoxic effects of the herbicide clomazone. The use of clomazone associated with dietholate for weed control on wheat is not recommended. The pyroxsulam was the herbicide that caused minor injuries to wheat.

Keywords: Lolium multiflorum; Raphanus sp.; safener; Triticum aestivum

\footnotetext{
${ }^{1}$ Recebido para publicação em 10/01/2016 e aceito em 15/03/2016.

${ }^{2}$ Universidade Federal da Fronteira Sul (UFFS), Câmpus Erechim, ERS 135 - km 72, n. 200, Erechim/RS, CEP 99700970, Cx. Postal 764. <leandro.galon@uffs.edu.br>.

${ }^{3}$ Universidade Federal de Viçosa (UFV), Mestrando do Departamento de Fitotecnia.
} 


\section{Introdução}

O trigo (Triticum aestivum L.) é a segunda principal cultura em produção no mundo e o cereal com uma das maiores áreas semeadas no mundo. A produção brasileira de trigo se concentra na região Sul, principalmente nos estados do Paraná (PR) e do Rio Grande do Sul (RS), com produtividade de grãos estimadas em $2.712 \mathrm{~kg} \mathrm{ha}^{-1}$ e $2.631 \mathrm{~kg} \mathrm{ha}^{-1}$ para cada estado, respectivamente (Conab, 2016). Estas produtividades são consideradas baixas quando comparadas com as obtidas em áreas experimentais ou em lavouras que adotam altos níveis tecnológicos. Isso tem sido atribuído ao manejo incorreto dos fatores de produção, principalmente pelo controle de plantas daninhas (Galon et al., 2015).

A interferência das plantas daninhas causa efeitos negativos sobre as culturas como a redução da qualidade e quantidade do produto colhido, devido à competição por recursos que podem se tornar limitantes (Agostinetto et al., 2008), liberação de aleloquímicos no ambiente (Lamego et al., 2013) e por hospedarem pragas e doenças (Vasconcelos et al., 2012).

Para o manejo das plantas daninhas infestantes de lavouras de trigo dispõe-se de alguns herbicidas, até então eficientes e seletivos, porém o uso repetitivo e continuo destes produtos acarretou na seleção de biótipos resistentes (Lamego et al., 2013). Para contornar este problema tem a necessidade da busca por novos herbicidas com mecanismos de ação diferenciados, mas eficiente no controle dessas espécies de plantas daninhas resistentes (Uizurrun et al., 2012) e que também apresentem seletividade a cultura do trigo. Neste sentido, o herbicida clomazone inibidor da biossíntese de carotenoides, pode ser uma alternativa interessante para o controle do azevém e de nabo resistente a outros mecanismos de ação (Bond et al., 2014), tornando-se uma importante ferramenta disponível para o manejo de plantas daninhas infestantes da cultura do trigo. Porém, quando aplicado em doses recomendadas, o clomazone pode causar intoxicação às plantas de trigo (Galon et al., 2015).

Estudos conduzidos com o arroz irrigado (Sanchotene, et al., 2010), algodão (Inoue, 2012) e milho (Karam et al., 2003) relatam que o tratamento de suas sementes com o safener dietholate causou a redução dos efeitos fitotóxicos do herbicida clomazone sobre as mesmas. Ressalta-se que o dietholate protege as plantas das injúrias provocadas pelo herbicida, evitando assim problemas de emergência, estande de plantas, bem como o próprio desenvolvimento da espécie. A seletividade das culturas devido à aplicação de dietholate decorre devido à inibição da enzima citocromo P-450 monoxigenase pelo safener evitando com que o clomazone seja transformado em sua forma ativa 5-OH-clomazone ou 5-ceto clomazone, na rota mevalonato não impedindo a síntese dos carotenóides (Ferhatoglu, 2005). Todavia, não existem informações na literatura sobre os efeitos do dietholate na redução dos efeitos tóxicos do clomazone em trigo.

O objetivo deste trabalho foi avaliar a fitotoxicidade do herbicida clomazone associado ou não ao dietholate aplicados à cultura do trigo.

\section{Material e Métodos}

$\mathrm{O}$ experimento foi instalado em casa de vegetação na Universidade Federal da Fronteira Sul (UFFS), Câmpus Erechim, em Erechim/RS, na latitude de $27^{\circ} 43^{\prime} \mathrm{S}$ longitude $52^{\circ} 17^{\prime} \mathrm{W}$ e com altitude de $753 \mathrm{~m}$. De acordo com a classificação de Köppen, o clima da região é classificado como Cfa, ou seja, subtropical úmido. O ensaio foi realizado durante os meses de agosto a outubro de 2014 em vasos de polietileno com capacidade para $8 \mathrm{dm}^{3}$ de substrato composto de Latossolo Vermelho Aluminoférrico típico, pertencente à unidade de mapeamento Erechim (Embrapa, 2013). A correção da fertilidade e os demais manejos e tratos culturais foram realizados conforme as recomendações técnicas para a cultura do trigo e do triticale (Embrapa, 2011). 
O delineamento experimental utilizado foi o inteiramente casualizado, arranjado em esquema fatorial $(5 \times 4)+2+2$, com quatro repetições. No fator A alocou-se as doses de dietholate $(0,120,240,360$ e $480 \mathrm{~g}$ por $100 \mathrm{~kg}$ de semente de trigo) e no $\mathrm{B}$ as doses de clomazone $\left(0,198,396\right.$ e $594 \mathrm{~g} \mathrm{ha}^{-1}$ aplicadas em pré-emergência), mais duas testemunhas (uma infestada com nabo e azevém e outra sem aplicação de herbicidas) e dois tratamentos adicionais aplicados em pós-emergência, o iodosulfuron-methyl ( $\left.5 \mathrm{~g} \mathrm{ha}^{-1}\right)$ e o pyroxsulam $\left(18 \mathrm{~g} \quad \mathrm{ha}^{-1}\right) . \quad \mathrm{O}$ iodosulfuron-methyl $\mathrm{e}$ pyroxsulam são os herbicidas mais utilizados na atualidade para o controle de plantas daninhas infestantes do trigo, por esse motivo foram utilizados como padrão para comparações com a melhor dose (quanto ao controle das plantas daninhas nabo e de azevém, dados não apresentados) da associação de clomazone + dietholate. Em cada unidade experimental foram semeadas 20 sementes de trigo da cultivar TBIO Itaipu, efetuando-se o desbaste das mesmas aos três dias após a emergência onde foi deixado dez plantas por vaso.

O tratamento das sementes de trigo com dietholate foi efetuado no dia anterior a semeadura sendo feita em sacos plásticos, diluindo o produto em $5 \mathrm{~mL}$ de água e aplicando-se o mesmo em $500 \mathrm{~g}$ de sementes. Posteriormente efetuou-se a agitação constante por 4 minutos, até que as sementes ficassem com cobertura homogênea. A aplicação de clomazone foi efetuada em pré-emergência, no mesmo dia da semeadura utilizando-se para isso um pulverizador costal de precisão, pressurizado a $\mathrm{CO}_{2}$, equipado com uma ponta de pulverização da série AXI 110.02, aspergindo um volume de calda de $200 \mathrm{~L} \mathrm{ha}^{-1}$. Os herbicidas iodosulfuron-methyl $\left(5 \mathrm{~g} \mathrm{ha}^{-1}\right)$ e pyroxsulam (18 $\mathrm{g} \mathrm{ha}^{-1}$ ) foram aplicados em pós-emergência, aos 14 dias após a emergência da cultura do trigo usando-se o mesmo pulverizador descrito anteriormente, porém com vazão de $150 \mathrm{~L} \mathrm{ha}^{-1}$ de calda. Ao iodosulfuron-methyl adicionou-se o espalhante adesivo a base de lauril éter sulfato de sódio (Hoefix - 0,3\% v/v) e ao pyroxsulam óleo vegetal (Veget Oil - 0,5 $\mathrm{L} \mathrm{ha}^{-1}$ ).

A fitotoxicidade dos tratamentos as plantas de trigo foram avaliadas aos 05, 19 e 33 dias após a emergência da cultura (DAE) ou aos 07, 14, 21 e 28 dias após a aplicação dos tratamentos (DAT), para os herbicidas constituintes dos tratamentos adicionais (SBCPD, 1995).

Aos 45 DAE foi realizada a avaliação da massa seca da cultura, acondicionando as mesmas em sacos de papel devidamente etiquetados, para posterior secagem em estufa de circulação forçada de ar, a $60 \pm 5 \mathrm{C}^{\circ}$, até a massa atingir peso constante.

Os resultados obtidos foram submetidos à análise de variância pelo teste $\mathrm{F}$, e havendo significância comparou-se as doses de clomazone associadas ao dietholate por regressões e os herbicidas padrão (iodosulfuronmethyl e pyroxsulam) juntamente com as testemunhas (infestada e sem herbicidas) e a melhor dose de clomazone + dietholate por teste de Tukey. Todos os testes foram efetuados a 5\% de probabilidade.

\section{Resultados e Discussão}

Ocorreu interação entre os fatores doses de clomazone e doses de dietholate para todas as variáveis avaliadas. $\mathrm{O}$ uso do dietholate reduziu os efeitos fitotóxicos do clomazone, independente da dose do herbicida e do protetor, na avaliação efetuada aos 5 DAE (Figura 1). A não aplicação do dietholate associado ao clomazone ocasionou incremento médio de $92,63 \%$ de fitotoxicidade ao trigo em comparação com a média de todas as doses do herbicida associado ao safener na primeira avaliação de fitotoxicidade. Karam et al. (2003) ao testarem diferentes doses de clomazone, sobre o híbrido de milho BRS 2223, com e sem dietholate, verificaram que o protetor possibilitou aumentar a dose do herbicida em até 1,6 vezes e mesmo assim manteve-se o mesmo nível de fitotoxicidade (50\%) aos 14 dias após a aplicação dos tratamentos. Sanchotene et al. 
(2010) observaram que o dietholate possibilitou aumentar em três vezes a dose de clomazone em relação àquela que ocasionou $50 \%$ de redução na massa fresca, sobre a cultivar de arroz IRGA 417.
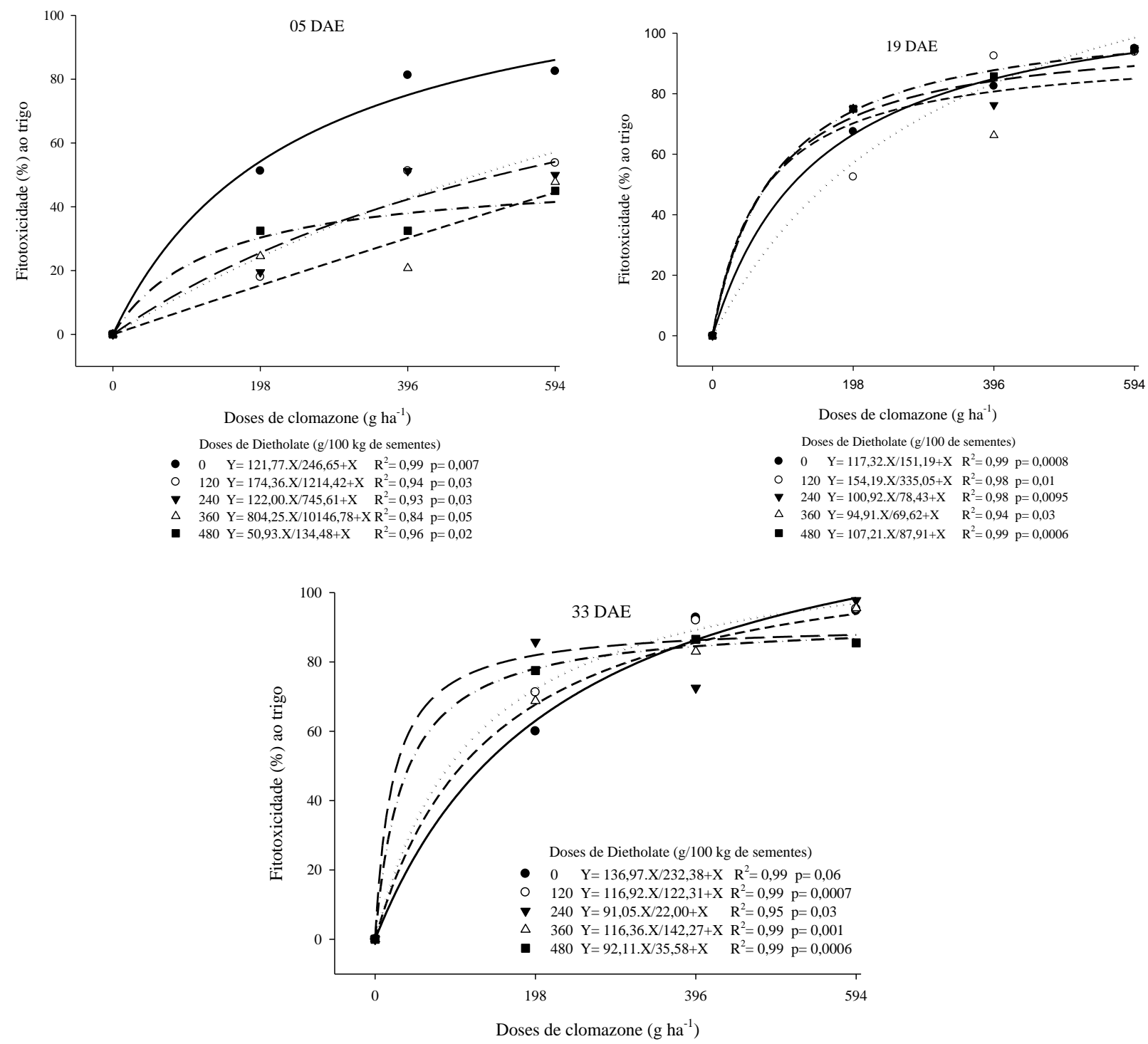

Figura 1. Fitotoxicidade (\%) na cultivar de trigo TBIO Itaipu, em função da aplicação de doses de clomazone associado a doses de dietholate, aos 05,19 e 33 dias após a emergência da cultura (DAE). UFFS, Câmpus Erechim, Erechim (RS), 2014.

Nas avaliações posteriores efetuadas aos 19 e 33 DAE observou-se resultados diferenciados aos obtidos aos 5 DAE (Figura 1). O dietholate não reduziu os efeitos fitotóxicos do clomazone e em alguns casos até os potencializou. Esse comportamento de aumento de fitotoxicidade com o uso do protetor foi observado já na menor dose $\left(198 \mathrm{~g} \mathrm{ha}^{-1}\right)$ do clomazone e nas quatro doses de dietholate, isso indica uma possível intoxicação do trigo com o próprio uso do safener. Takano et al. (2012) ao avaliarem o efeito de doses de dietholate em seis cultivares de feijão, expostas ou não a aplicação de clomazone, verificaram que o tratamento das 
sementes com protetor provocou redução no índice de velocidade de germinação, e para algumas cultivares ocorreu redução no crescimento, sendo os danos nestas variáveis respostas ainda maiores quando se associou com a aplicação de herbicida.

Rizzardi e Serafini (2001) ao testarem o efeito do anidrido naftálico $\left(5 \mathrm{~g} \mathrm{~kg}^{-1}\right)$ como protetor em aveia branca cultivar UPF-16, visando promover a seletividade a herbicidas observaram que o clomazone na dose de $1000 \mathrm{~g}$ ha $^{-1}$ também apresentou efeitos fitotóxicos elevados, em torno de $80 \%$ aos 30 dias após a aplicação do herbicida. Silva et al. (2011) ao tratarem sementes de trigo cultivar Ônix com o protetor fluxofenim $(40 \mathrm{~mL}$ por $100 \mathrm{~kg}$ de sementes) e a aplicação de S-metolachlor (1440 $\mathrm{g} \mathrm{ha}^{-1}$ ), verificaram que o protetor proporcionou acúmulo de até $70 \%$ a mais de massa seca da parte aérea, porém os autores consideraram baixa seletividade à cultura, evidenciando a necessidade de mais estudos.

Analisando-se a Figura 2, quando o trigo foi cultivado sem aplicação de herbicida em todas as doses de dietholate, o uso do protetor ocasionou maior acumulo de massa seca. Observou-se um acumulo médio de $187 \%$ ao se comparar o uso de doses de dietholate contra o não uso do safener, na ausência de tratamento herbicida. Esse fato pode estar associado a proteção que o dietholate ocasiona as culturas, já que o mesmo é um inseticida usado em tratamentos de sementes. De modo geral o aumento das doses de clomazone associado as doses de dietholate ocasionou redução da quantidade de massa seca acumulada pelo trigo. Ressalta-se ainda que os tratamentos que não se aplicou o dietholate ocorreu menor produção de massa seca do trigo, em todas as doses aplicadas de clomazone. Esse efeito também é relatado por Mistura et al. (2008) em plântulas de arroz, e Takano et al. (2012) em plântulas de feijão.

Os resultados demonstram ao se comparar as doses de dietholate, dentro de cada dose de clomazone que quando as plantas de trigo receberam a aplicação do herbicida nas doses de 198, 396 e $594 \mathrm{~g} \mathrm{ha}^{-1}$, associado ao dietholate, aumentou o acúmulo de massa seca, independente das doses do safener, se comparado a ausência do protetor (Figura 2). No entanto não se pode recomendar a aplicação de clomazone associado ao dietholate, em nenhuma das doses estudadas, para o controle de plantas daninhas infestantes do trigo, uma vez que a associação de clomazone com dietholate foi mais prejudicial do que manter as plantas de trigo sem o uso de produtos (testemunha sem herbicida e sem dietholate).

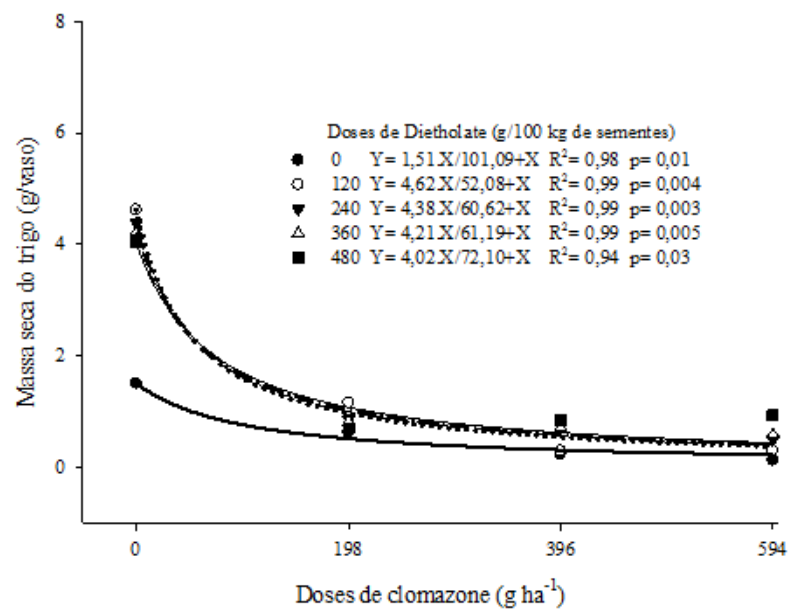

Figura 2. Massa seca da parte aérea da cultivar de trigo TBIO Itaipu em função da aplicação de doses de clomazone associado a doses de dietholate, aos 45 dias após a emergência da cultura. UFFS, Câmpus Erechim, Erechim (RS), 2014.

Na Tabela 1 estão apresentados os resultados de fitotoxicidade ao trigo aos 07,14 , 21 e 28 DAT ocasionada pelos tratamentos adicionais comparados a melhor dose resposta de clomazone + dietholate em relação ao controle de plantas daninhas, em experimento conduzido anteriormente (dados não apresentados). Em todas as avaliações verificou-se que o clomazone associado ao dietholate apresentou os maiores níveis de fitotoxicidade, ou seja, comprometeu de forma irreversível o crescimento e desenvolvimento da cultura.

Aos 28 DAT, o pyroxsulam reduziu os efeitos fitotóxicos a cultura em comparação aos 
21 DAT, porém o iodosulfuron-methyl não apresentou o mesmo comportamento, aumentando a fitotoxicidade no decorrer das avaliações, evidenciando que o pyroxsulam foi o herbicida menos fitotóxico à cultura do trigo (Tabela 1). Vargas e Roman (2005) não observaram sintomas de fitotoxicidade causada pela aplicação de iodosulfuron-methyl em pós- emergência da cultura do trigo, em condições de campo. Ressalta-se, no entanto que os experimentos foram efetuados em vasos plásticos em casa de vegetação, onde a injúria dos herbicidas pode ser maior que em situações de campo, já que se tem menor volume de solo disponível ao desenvolvimento das plantas.

Tabela 1. Fitotoxicidade (\%) ocasionada a cultivar de trigo TBIO Itaipu em função da aplicação de herbicidas aos 7, 14, 21 e 28 dias após a aplicação dos tratamentos (DAT). UFFS, Câmpus Erechim, Erechim (RS), 2014.

\begin{tabular}{lccccc}
\multicolumn{1}{c}{ Tratamentos } & Dose $\left(\mathrm{g} \mathrm{ha}^{-1}\right)$ & 7 DAT & $14 \mathrm{DAT}$ & $21 \mathrm{DAT}$ & $28 \mathrm{DAT}$ \\
\hline Testemunha infestada & --- & $00,00 \mathrm{c}^{1}$ & $00,00 \mathrm{c}$ & $00,00 \mathrm{c}$ & $00,00 \mathrm{~d}$ \\
Testemunha capinada & --- & $00,00 \mathrm{c}$ & $00,00 \mathrm{c}$ & $00,00 \mathrm{c}$ & $00,00 \mathrm{~d}$ \\
Clomazone + dietholate & $396+240$ & $76,25 \mathrm{a}$ & $83,25 \mathrm{a}$ & $72,50 \mathrm{a}$ & $86,25 \mathrm{a}$ \\
Iodosulfuron-methyl & 05 & $05,00 \mathrm{~b}$ & $14,75 \mathrm{~b}$ & $33,75 \mathrm{~b}$ & $36,25 \mathrm{~b}$ \\
Pyroxsulam & 18 & $02,75 \mathrm{bc}$ & $11,50 \mathrm{~b}$ & $25,00 \mathrm{~b}$ & $18,75 \mathrm{c}$ \\
\hline Média Geral: & --- & 16,80 & 21,90 & 26,25 & 28,25 \\
CV $(\%):$ & --- & 7,43 & 11,69 & 15,16 & 18,63 \\
\hline
\end{tabular}

${ }^{1}$ Médias seguidas de mesmas letras minúsculas na coluna não diferem entre si, pelo teste de Tukey a 5\% de probabilidade.

A massa seca de trigo, colhida aos 45 DAE, esta apresentada na Tabela 2. Todos os herbicidas reduziram o acúmulo de massa seca de trigo, mas diferiram estatisticamente apenas da testemunha capinada. Dentre os herbicidas o pyroxsulam foi o tratamento que menos influenciou negativamente no desenvolvimento do trigo, produzindo $183 \%$ a mais de massa seca ao se comparar com a média da aplicação de clomazone + dietholate e de iodosulfuronmethyl.
Destaca-se ainda que ocorre a necessidade de se fazer o controle do nabo e do azevém infestante do trigo, já que ao se comparar a testemunha infestada (sem controle) com os tratamentos que foram controlados, observou-se acréscimo médio de massa seca de $71,5 \%$. Convém salientar que reduções na massa seca foliar de plantas pode acarretar em menor potencial fotossintético e isso ocasionar decréscimos no crescimento e desenvolvimento das culturas (Takano et al., 2012).

Tabela 2. Massa seca de parte aérea de trigo cultivar TBIO Itaipu em função da aplicação de herbicidas aos 45 dias após a emergência. UFFS, Câmpus Erechim, Erechim (RS), 2014.

\begin{tabular}{lcc}
\hline \multicolumn{1}{c}{ Tratamentos } & $\begin{array}{c}\text { Dose } \\
\mathrm{g} \mathrm{ha}^{-1}\end{array}$ & $\begin{array}{c}\text { Massa seca do trigo } \\
(\mathrm{g} / \mathrm{vaso})\end{array}$ \\
\hline Testemunha infestada & --- & $1,50 \mathrm{~b}^{1}$ \\
Testemunha capinada & --- & $6,28 \mathrm{a}$ \\
Clomazone + dietholate & $396+240$ & $0,86 \mathrm{~b}$ \\
Iodosulfuron-methyl & 05 & $0,80 \mathrm{~b}$ \\
Pyroxsulam & 18 & $2,35 \mathrm{~b}$ \\
\hline Média Geral & & 2,36 \\
\hline $\mathrm{CV}(\%)$ & & 44,50 \\
\hline${ }^{1}$ Médias seguidas de mesmas letras minúsculas na coluna não diferem entre si, pelo teste de Tukey a 5\% de probabilidade.
\end{tabular}

Trabalhos têm demonstrado maior acumulo de massa seca do trigo quando tratos com herbicidas, associados a diferentes protetores de sementes. A utilização de fluxofenim como safener para à aplicação do herbicida S-metolachlor ocasionou valores de 
massa seca da parte aérea e raiz mais elevados nas parcelas que receberam o tratamento de sementes, com acrescimento de até $70 \%$ de massa seca da parte aérea ao se comparar com a ausência do tratamento de sementes (Silva et al., 2011). Cataneo (2001) ao aplicar o herbicida fenoxaprop-p-ethyl associado ao safener mefenpyr-diethyl em seis cultivares de trigo observou menor acúmulo de massa verde das plantas quando a cultura foi submetida a aplicação do herbicida sem utilização do protetor.

Ressalta-se que tanto o trabalho de Cataneo (2001) quanto o realizado por Silva et al. (2011) relataram que o trigo ao ser tratado com diferentes herbicidas, fenoxaprop-p-ethyl e S-metolachlor, ao serem aplicados em diferentes doses e sobre várias cultivares, sem adição de protetor, demonstraram severas fitotoxicidades e diminuição do acúmulo de massa seca da cultura, o que corrobora com os resultados encontrados no presente estudo. No entanto novos estudos necessitam ser efetuados para se avaliar a campo a possibilidade do uso de clomazone para o controle de plantas daninhas infestantes do trigo e a seletividade à cultura.

\section{Conclusões}

O dietholate não apresentou capacidade de proteger o trigo dos efeitos fitotóxicos do herbicida clomazone. Não é recomendado o uso do clomazone associado ao diethole para controle na pós-emergência do trigo. $\mathrm{O}$ pyroxsulam foi o herbicida que causou menores injúrias à cultura.

\section{Agradecimentos}

Ao Conselho Nacional de Desenvolvimento Científico e Tecnológico (CNPq) e à Fundação de Amparo à Pesquisa do Estado do Rio Grande do Sul (FAPERGS), pelo auxílio financeiro à pesquisa (Processos n. 482144/2012-2/CNPq e 12/2265-3/FAPERGS) e pelas concessões de bolsas.

\section{Referências}

Agostinetto, D.; Rigoli, R.P.; Schaedler, C.E.; Tironi, S.P.; Santos, L.S. Período crítico de competição de plantas daninhas com a cultura do trigo. Planta Daninha, v.26, n.2, p.271-278, 2008 .

Bond, Jason A.; Eubank, Thomas W.; Bond, Robin C.; Golden, Bobby R.; Edwards, H. Matthew. Glyphosate-resistant italian ryegrass (Lolium perenne ssp. multiflorum) control with fall-applied residual herbicides. Weed Technology, v. 28, p.361-370, 2014.

Cataneo, A.C. Estudos fisiológicos e bioquímicos da ação do mefenpyr-diethyl na desintoxicação do herbicida fenoxaprop-p-ethyl em cultivares de trigo (Triticum aestivum L.). 2001. 88f. Tese (Livre Docência em Ciências Biológicas-Área de Bioquímica) - Instituto de Biociências, Universidade Estadual Paulista, Botucatu, 2001.

Companhia Nacional de Abastecimento CONAB. Séries históricas de área plantada, produtividade e produção. Disponível em: em: $<$ http://www.conab.gov.br $>$. Acesso em: 10 mar. 2016.

Empresa Brasileira de Pesquisa Agropecuária EMBRAPA. Sistema brasileiro de classificação de solos. 3.ed. Brasília, 2013. 353p.

Empresa Brasileira de Pesquisa Agropecuária EMBRAPA. Sistemas de produção / Embrapa Agropecuária Oeste. Informações técnicas para trigo e triticale - safra 2012. Dourados: Embrapa Agropecuária Oeste, 2011. 204 p.

Ferhatoglu, Y.; Avdiushk, S.; Barrett, M. The basic for safening of clomazone by phorate insecticide in cotton and inhibitors of cytochrome P450s. Pesticide Biochemistry and Physiology, v.81, n.1, p.59-70, 2005.

Galon, L.; Castoldi, C.T.; Forte, C.T.; Kujawiski, R.; De David, F.A.; Perin, G.F. Eficácia e fitotoxicidade de herbicidas aplicados para manejo de plantas daninhas infestantes do 
trigo. Revista Brasileira de Herbicidas, v.14, n.2, p.128-140, 2015.

Inoue, M.H.; Araújo, T.D.C.; Mendes, K.F.; Ben, R.; Conciani, P.A. Eficiência de dietholate e bioestimulante isolados e associados no tratamento de sementes de algodoeiro adensado com clomazone aplicado em pré-emergência. Revista de Ciências Agro-Ambientais, v.10, n.2, p.163-172, 2012.

Karam, D.; Carneiro, A.A.; Albert, L.H.; Cruz, M.B.; Costa, G.T.; Magalhães, P.C. Seletividade da cultura do milho ao clomazone por meio do uso de dietholate. Revista Brasileira de Milho e Sorgo, v.2, n.1, p.72-79, 2003.

Mistura, C.C.; Branco, J.C.; Freitas, D.A.C.; Rosenthal, M.D.; Moraes, D.M.; Oliveira, A.C. Influência do protetor de sementes dietil fenil fosforotioato sobre plântulas de arroz (Oryza sativa L.). Revista Brasileira de Agrociência, v.14, n.2, p.231-238, 2008.

Lamego, F.P.; Ruchel, Q.; Kaspary, T.E.; Gallon, M.; Basso, C.J.; Santi, A.L. Habilidade competitiva de cultivares de trigo com plantas daninhas. Planta Daninha, v.31, n.3, p.521531, 2013.

Rizzardi, M.A.; Serafini, M.C. Ação do anidrido naftálico na seletividade de herbicidas aplicados para controle de azevém em aveia-branca. Planta Daninha, v.19, n.3, p.367-374, 2001.

Sanchotene, D.M.; Kruse, N.D.; Avila, L.A.; Machado, S.L.O.; Nicolodi, G.A.; Dornelles, S.H.B. Efeito do protetor dietholate na seletividade de clomazone em cultivares de arroz irrigado. Planta Daninha, v.28, n.2, p.339-346, 2010.

Silva, J.R.V.; Martins, D.; Cataneo, A.C.; Silva, J.V.C.; Ferreira, L.C.; Souza, G.S.F. et al. Uso de fluxofenim em trigo como protetor ao herbicida S-metolachlor. Arquivos do Instituto Biológico, v.78, n.3, p.401-407, 2011.

SBCPD - SOCIEDADE BRASILEIRA DA CIÊNCIA DAS PLANTAS DANINHAS. Procedimentos para instalação, avaliação e análise de experimentos com herbicidas. Londrina: $1995.42 \mathrm{p}$.

Takano, H.K.; Oliveira Jr., R.S.; Constantin, J.; Oliveira Neto, A.M.; Braz, G.B.P.; Dan, H.A. et al. Potencial de utilização do dietholate como protetor de clomazone em feijoeiro comum. Revista Brasileira de Herbicidas, v.11, n.3, p.305-315, 2012.

Uizurrun, P.D.; Leaden, M.I. Análisis de la sensibilidad de biotipos de Lolium multiflorum a herbicidas inhibidores de la enzima als, ACCasa y glifosato. Planta Daninha, v.30, n.3, p.667-673, 2012.

Vargas, L.; Roman, E.S. Seletividade e eficiência de herbicidas em cereais de inverno. Revista Brasileira de Herbicidas, v.4, n.3, p.110, 2005.

Vasconcelos, M.C.C.; Silva, A.F.A.; Lima, R.S. Interferência de plantas daninhas sobre plantas cultivadas. Agropecuária Científica no Semiárido, v.8, n.1, p.1-6, 2012. 